\title{
Iluminasi, Eksegesis, dan Doa
}

\author{
Deky Hidnas Yan Nggadas \\ Sekolah Tinggi Teologi Huperetes Batam \\ deky_nggadas@yahoo.com
}

\begin{abstract}
This article is intended to discuss the doctrine of illumination in light of some current debates among scholars. In addition to the critical evaluation of the debate, I would like to contribute to this discussion by providing my own exegetical observation on various biblical texts. I will conclude this article with a brief review of the relationship between illumination and prayer.
\end{abstract}

Keywords: Holy Spirit, illumination, prayer, biblical exegesis, hermeneutics.

\begin{abstract}
Abstrak: Artikel ini dimaksudkan untuk membahas doktrin iluminasi terutama tentang beberapa perdebatan saat ini di antara para sarjana. Selain evaluasi kritis terhadap debat, saya ingin berkontribusi pada diskusi ini dengan memberikan pengamatan eksegetikal saya sendiri pada berbagai teks alkitabiah. Saya akan menyimpulkan artikel ini dengan tinjauan singkat tentang hubungan antara iluminasi dan doa
\end{abstract}

Kata-kata kunci: Roh Kudus, iluminasi, doa, exegesis, hermeneutik.

\section{A. Pendahuluan}

Tadinya saya tidak pernah membayangkan bahwa iluminasi dapat ditulis untuk dipublikasikan di sebuah jurnal ilmiah. Semua orang sudah mengetahuinya. Saya, mungkin Anda juga, mengasumsikan begitu. Lalu saya teringat pengalaman berkhotbah di sebuah gereja. Sebelum berkhotbah, saya berdoa memohon iluminasi Roh Kudus. Dengan asumsi tadi, saya tidak mengantisipasi bahwa setelah ibadah itu selesai, salah seorang majelis bertanya: "Iluminasi itu apa, pak?"

Sekitar 15 tahun yang lalu (2003), saya membaca buku Djaka Christianto Silalahi, berjudul: Rhema: Istilah Baru untuk Kekuatan Batin? (terbit 2001). Buku ini adalah sebuah karya apologetik untuk membela teologi rhema yang diajarkan David Yonggi Cho yang dikritik oleh Herlianto melalui bukunya: Teologi Sukses. Pada dasarnya, Silalahi mengklaim bahwa teologi rhema lebih akomodatif untuk diterima ketimbang konsep iluminasi. Ia berargumen, demikian:

Iluminasi adalah konsep yang menyatakan tindakan Roh Kudus dalam diri pembaca Alkitab sehingga ia dapat memahami isinya. Sayangnya, konsep iluminasi ini memiliki prasyarat (informal dan implisit) yang berat, yaitu seseorang harus menguasai berbagai metode penafsiran Alkitab (hermeneutika) untuk menyajikan kepada khalayak luas iluminasi yang 'diterimanya' dari Roh Kudus. Akibatnya, iluminasi secara umum lebih banyak dikuasai dan dihasilkan oleh para elit tertentu saja. Eksesnya adalah semangat elitisme. ${ }^{1}$

${ }^{1}$ Djaka Christianto Silalahi, Rhema: Istilah Baru untuk Kekuatan Batin? (Yogyakarta: Andi, 2001), 53-54. 
Saya telah menulis mengenai teologi rhema yang diajarkan Cho dalam sebuah esai tersendiri. ${ }^{2}$ Tetapi, konsep iluminasi yang dipahami kemudian digambarkan ulang oleh Silalahi di atas adalah sebuah karikatur. Pemahaman dan ketrampilan hermeneutis bukan prasyarat iluminasi. Sebaliknya iluminasi merupakan prasyarat dari hermeneutik. Kebutuhan akan proses penafsiran Alkitab dengan metode yang baik merupakan suatu keharusan dimana seluruh proses tersebut harus dilakukan dengan kebergantungan atas karya Roh Kudus yang memberikan pencerahan (iluminasi) untuk memahami firman Tuhan secara tepat. Bahwa ada bahaya elitisme intelektual, itu bukan merupakan alasan untuk membuang keharusan menekuni proses penafsiran. Dan tentu saja, kecenderungan untuk menghindari studi dan kerja keras dalam menyelidiki firman Tuhan, seperti yang terimplikasi dalam komentar Silalahi di atas, tidak pernah merupakan buah dari tuntunan Roh Kudus. Menyodorkan teologi rhema sebagai pengganti keharusan studi dan penyelidikan yang saksama akan firman Tuhan, bukan hanya menyodorkan sebuah teologi yang salah bahkan berbahaya, melainkan juga merupakan cerminan dari kemalasan yang dibungkus dengan jubah kesungguhan.

Di sisi lain, doktrin iluminasi dalam kaitan dengan proses penafsiran Alkitab bukanlah sebuah doktrin tanpa masalah. Seperti yang akan saya diskusikan, perdebatan para ahli mengenai doktrin ini bisa dikatakan belum final. Saya akan menggambarkannya dengan membahas tentang perdebatan Daniel P. Fuller (salah seorang pendiri Fuller Theological Seminary) dan Millard J. Erickson (Distinguished Professor of Theology di Western Seminary). Selain komentar evaluatif untuk perdebatan tersebut, saya hendak memberikan kontribusi melalui ulasan eksegetis terhadap bagian-bagian PL dan PB yang dapat diacu untuk berbicara mengenai doktrin iluminasi.

\section{B. Observasi Eksegetis}

Iluminasi ("pencerahan," dan "penerangan") berarti karya Roh kudus yang memampukan kita untuk menyukai, mengerti, dan menerima (mempercayai) firman Tuhan (Alkitab) serta mengaplikasikannya dalam kehidupan kita setiap hari. Ada sejumlah teks dari PL maupun PB yang relevan dengan definisi ini yang akan saya diskusikan secara ringkas di bawah ini.

\section{Mazmur 1, 19, dan 119}

Mazmur 1 berbicara tentang kontras antara orang benar dan orang jahat. Orang benar adalah orang yang menyukai dan mencintai serta dikuasai oleh Taurat Tuhan. Begitu cintanya terhadap Taurat Tuhan, sehingga ia mendedikasikan hidupnya untuk "merenungkan Taurat itu siang dan malam" (ay. 2). Taurat adalah petunjuk, instruksi, pengajaran, dan panduan dari Tuhan bagi umat-Nya untuk hidup menyenangkan Dia. Taurat Tuhan bermanfaat untuk menjauhkan orang benar dari daya tarik dosa. Perhatikan progres dari daya tarik dosa: "berjalan", "berdiri," dan "duduk" (ay. 1). D.L. Moody menyatakan, "Kitab ini (Alkitab) akan menjauhkan Anda dari dosa atau dosa akan menjauhkan Anda dari kitab ini."3

\footnotetext{
2 Deky Hidnas Yan Nggadas, "Logos dan Rhema menurut David Yonggi Cho: Teologi yang Sembrono dan Berbahaya," dalam Kembong Mallisa', dkk. (eds.), Berjuanglah Sampai Akhir: Kumpulan Tulisan dalam Rangka Dies Natalis SETIA ke-30 (Jakarta: Delima, 2017), 93-108.

${ }^{3}$ Elmer Towns, Foundational Doctrines of the Faith (Elkton, MD.: Ephesians Four Ministries, 2000), 12.
} 
Kata hagah yang diterjemahkan dalam bahasa Indonesia dengan "merenungkan," (ay. 2) sebenarnya dapat juga berarti "memikirkan," dan "mengucapkan kembali dengan bersuara." Kata ini mengasumsikan satu set ide yang mencakup: membaca, mempelajari, meditasi, dan mengutipnya kembali. ${ }^{4}$ Dedikasi yang tekun untuk mempelajari Taurat Tuhan "siang dan malam," berasal dari kesukaan yang besar (affection) terhadapnya. ${ }^{5}$

Kita kehilangan ekspresi penting dari satu kata bahasa Ibraninya dalam terjemahan bahasa Indonesia terhadap ayat 2, yaitu kata ubetorato (LXX: to nomo auto), yang berarti "Tauratnya" (his Torah). Ekspresi ini dapat berarti "Tauratnya Tuhan" atau "Tauratnya si Pemazmur itu sendiri." Ambiguitas ini, mengindikasikan bahwa Pemazmur bukan hanya memandang Taurat itu dari (atau milik) Tuhan, melainkan juga menjadikannya sesuatu yang menyatu dengan dirinya. Ia memandangnya sebagai kepunyaan yang menyukakan hatinya dan yang ia renungkan siang dan malam. ${ }^{6}$ Ia mendefinsikan dirinya dalam terang Taurat dan mendefinisikan Taurat dalam terang integralitas Taurat itu dalam seluruh eksistensinya.

Pemazmur menggambarkan orang yang demikian seperti "pohon yang ditanam di tepi aliran air, yang mengasilkan buahnya pada musimnya, dan yang tidak layu daunnya, apa saja yang diperbuatnya berhasil" (ay. 3; bnd. Yer. 17:5-8). Memang ekspresi tentang kesuksesan di sini, dalam konteks hikmat PL, merujuk kepada kesuskesan material (mis. Mzm. 37:25; 128:3; 144:12-14; dan isi Kitab Amsal). Tetapi esensi dari pengungkapan ini sebenarnya jauh lebih kaya daripada sekadar kesuksesan material. Sebab kita membaca pengungkapan yang paralel dalam Yosua 1:7-8, dan yang dimaksudkan di situ adalah bahwa Yosua akan sukses dalam memenuhi panggilan dan tugas yang diberikan Tuhan kepadanya, yaitu membawa Israel memasuk tanah perjanjian (Kanaan). Jadi, orang yang kehidupannya didefinisikan oleh Taurat Tuhan akan memenuhi tujuan Tuhan atau kehendak Tuhan dalam hidupnya.

Gagasan-gagasan di atas terungkap kembali dalam Mazmur 19 yang berbicara mengenai keindahan, kebenaran, kemurnian, dan kesempurnaan Taurat Tuhan (ay. 811). Taurat Tuhan menjadi dasar dari sikap hidup yang takut akan Tuhan (ay. 9) bahkan menjadi dasar untuk mengetahui tentang kesesatan dan kesalahan (ay. 13) serta melindungi dari kejahatan (ay. 14). Taurat Tuhan mendatangkan kesegaran, hikmat, kesukaan, dan membangkitkan kekaguman (ay. 8-11). Sama seperti Mazmur $1: 3$, pasal ini juga berbicara tentang "orang yang berpegang padanya mendapat upah yang besar" (ay. 12).

Keutamaan dan kesukaan yang besar akan Taurat serta dorongan untuk mempelajarinya juga dibicarakan dalam keseluruhan pasal 119. Dalam ayat 18, Pemazmur berdoa demikian: "Singkapkanlah mataku, supaya aku memandang keajaiban-keajaiban dari Taurat-Mu." Ayat ini sangat penting untuk mengingatkan kita bahwa hanya dengan pertolongan supernatural dari Tuhan, seseorang dapat melihat keindahan Taurat Tuhan yang menjadikannya memiliki kesukaan (Mzm. 1:2) dan kerinduan yang hebat (Mzm. 119:20) untuk mempelajarinya. Doa senada juga dinyatakan pemazmur tatkala ia memohon agar "Perlihatkanlah kepadaku, ya Tuhan, petunjuk ketetapan-ketetapan-Mu, aku hendak memegangnya sampai akhir. Buatlah

\footnotetext{
${ }^{4}$ Bruce K. Waltke and Charles Yu, An Introduction to the Old Testament: An Exegetical, Canonical, and Thematic Approach (Grand Rapids, Michigan: Zondervan, 2007), 885.

5 Tremper Longman III, Psalms: Introduction and Commentary (Epub version; TOTC; Nottingham: IVP, 2014).

${ }^{6}$ Mayer I. Gruber, Rashi's Commentary on Psalms (Leiden-Boston: Brill, 2004), 173.
} 
aku mengerti, maka aku akan memegang Tauratmu; aku hendak memeliharanya dengan segenap hati" (119:33-34).

Tuhan mengaruniakan kesukaan, kekaguman, pengertian, kerinduan untuk taat, serta keteguhan untuk berpegang pada firman Tuhan hingga akhir ketika umat-Nya berdoa memintanya dengan penuh kerendahan hati kepada-Nya.

\section{Yesaya 6:9-10 dan Injil Sinoptik ${ }^{7}$}

Yesaya 6:9-10 merupakan teks yang berbicara mengenai ketegartengkukan (obduracy) Israel dalam memberikan respons yang seharusnya terhadap pemberitaan Yesaya (bnd. Ul. 29:3; Yer. 5:21, 23; Yeh. 12:2). Di dalam MT, ketegartengkukan tersebut secara jelas dipresentasikan sebagai sesuatu yang dilakukan Allah di dalam kedaulatan-Nya. Di dalam LXX, ketegartengkukan itu merupakan akibat dari sikap Israel sendiri yang terus-menerus berlaku jahat di hadapan Tuhan.

Di dalam PB, Yesaya 6:9-10 dikutip baik oleh para penulis Injil maupun Paulus ketika berbicara mengenai orang-orang yang memberikan respons negatif terhadap Tuhan. Markus 4:12 dan Matius 13:13-15 mengutip teks di atas untuk berbicara mengenai alasan Yesus mulai mengajar dengan menggunakan perumpamaanperumpamaan. Perbedaannya, Markus mengutip teks tersebut dari naskah MT, sedangkan Matius mengutipnya dari naskah LXX. Dalam kutipan Markus, Yesus mengajar dalam bentuk perumpamaan supaya (Yun. hina) audiensnya tidak mengerti $(4: 12),{ }^{8}$ sedangkan menurut Matius, Yesus menggunakan perumpamaanperumpamaan karena (Yun. hoti) mereka tidak mengerti (13:13). ${ }^{9}$ Lukas juga mengutip dari Yesaya 6:9-10 walau bukan dalam bentuk formalnya. Di dalam kutipan Lukas, Yesus tidak menggunakan perumpamaan-perumpamaan untuk menghalangi audiens-Nya mengerti akan rahasia-rahasia kerajaan Allah dan dengan demikian menghalangi mereka untuk bertobat dan mendapatkan pengampunan dosa. Sebaliknya, yang menghalangi mereka adalah Iblis. Hal ini bisa dideduksi dari penggunaan kutipan yang ditujukan bukan kepada alasan penggunaan perumpamaan sebagai cara pengajaran, melainkan arti dari perumpamaan tentang penabur (Luk. $8: 4-15) \cdot{ }^{10}$

Ketiga teks di atas secara jelas menandaskan bahwa perihal mengerti rahasia kerajaan Allah kemudian memberikan respons yang sepatutnya merupakan karunia atau pemberian Allah Allah yang berdaulat. Dan karunia Allah ini diberikan kepada para murid (Mrk. 4:11; Mat. 13:11; Luk. 8:10).

Selanjutnya, Yesaya 6:9-10 juga dikutip dalam Yohanes 12:40 untuk menggambarkan penolakan demi penolakan Israel terhadap pemberitaan Yesus melalui berbagai tanda dalam Yohanes 1-11. Tanda-tanda (Yun. ta semeia)

${ }^{7}$ Craig A. Evans, To See and Not Perceive: Isaiah 6.9-10 in Early Jewish and Christian Interpretation (JSOT Supp. 64; Sheffield: JOST Press, 1989). Evans menggeluti eksegesis terhadap teks ini dalam tradisi Yahudi maupun Kristen.

${ }^{8}$ Meskipun dalam teks di atas Markus memberikan penekanan pada kedaulatan Allah, namun dalam bagian lain, Markus menggunakan Yesaya 6:9-10 dalam penekanan pada tanggung jawab manusia (Mrk. 8:18).

${ }^{9}$ Deky Hidnas Yan Nggadas, "Hubungan Kedaulatan Allah dan Tanggung Jawab Manusia: Suatu Studi Eksegesis Matius 13:10-17," dalam Jurnal Amanat Agung Volume 4, Nomor 1 (Juni, 2008).

10 Evans, To See and Not Perceive, 117. Evans juga mendiskusikan kutipan Yesaya 6:9-10 dalam Kisah 28:26-27 yang digunakan dalam konteks penekanan bahwa perihal bangsa-bangsa lain "mendengar" berita Injil, merupakan bukti bahwa keselamatan diperuntukkan juga bagi bangsabangsa non Yahudi. 
merupakan sarana pewahyuan yang menyingkapkan identitas dan misi Yesus. ${ }^{11}$ Namun, semakin mereka melihat tanda-tanda tersebut, semakin mereka menolak Yesus bahkan mereka bersepakat untuk membunuh Yesus setelah Yesus membangkitkan Lazarus $(11: 57 ; 12: 9-11)$.

Jadi, dalam Yesaya 6:9-10 berikut teks-teks yang mengutipnya, kita mendapati gagasan yang sangat jelas bahwa perihal mengerti akan pewahyuan dari Tuhan tidak dapat dipisahkan dari memberikan repons yang dikehendaki-Nya, dan itu merupakan karunia dari Tuhan. Tuhan berdaulat untuk memberikan karunia tersebut hanya kepada para murid-Nya. Tetapi, pada saat yang sama seseorang tidak dapat menuduh Allah secara membabi buta menghalangi orang-orang untuk mendapatkan pengertian serta memberikan respons yang positif. Teks-teks di atas memperlihatkan bahwa kondisi keberdosaan dan kejahatan mereka menghalangi mereka sedemikian rupa sehingga pewahyuan demi pewahyuan diberitakan kepada mereka, namun mereka tetap tidak mengerti dan bahkan berkeras hati menolak Tuhan.

Menariknya, dalam sejumlah kesempatan, Yesus mengkonfrontasi sikap negatif para pemimpin Yahudi dengan pertanyaan retoris ini: "Tidakkah kamu baca..." (Mat. 12:3, 5; 19:4; 22:31; Mrk. 12:26; Luk. 6:3). Pertanyaan-pertanyaan retoris ini mengasumsikan bahwa mereka seharusnya dapat memahami PL yang mereka baca, kemudian mereka dapat melihat signfikansinya dalam kehidupan dan pengajaran Yesus. Kegagalan mereka untuk memberikan respons positif terhadap Yesus, tidak berarti bahwa mereka kehilangan kemampuan intelektual mereka untuk mengerti apa yang mereka baca. Perihal penolakan mereka terhadap Yesus merupakan bukti bahwa mereka hanya memiliki pengertian yang fragmentaris (halftruth). Pengertian yang utuh akan PL seharusnya memimpin mereka untuk percaya kepada Yesus. Pengertian intelektual melalui pembacaan akan PL dan sikap positif terhadap Yesus merupakan suatu kesatuan yang utuh. Mengerti PL tanpa percaya kepada Yesus, sama dengan tidak mengerti. Jadi, ketegartengkukan yang diidentifikasi dengan "tidak mengerti," "buta," dan "tidak mendengar," tentu saja bukan persoalan ketidakmengertian intelektual semata. Teks-teks di atas berbicara tentang totalitas sikap seseorang terhadap pewahyuan Tuhan.

\section{Tulisan-tulisan Yohanes}

Saya sudah mendiskusikan mengenai Yohanes 12:40 yang berbicara mengenai penolakan terhadap pewahyuan Allah di dalam pelayanan Yesus Kristus. Di sini saya akan mendiskusikan tulisan-tulisan Yohanes yang berbicara mengenai karya Roh Kudus dalam memberikan iluminasi bagi orang-orang percaya untuk mengerti dan meresponsi pewahyuan Allah secara positif.

Yohanes 14-16 merupakan kata-kata perpisahan Yesus dengan para muridNya sebelum ia menghadapi jalan salib. Di dalamnya Yesus menjanjikan untuk mengutus Roh Kudus. Peran Roh Kudus yang dibicarakan dalam pasal-pasal ini, yaitu: menyertai para murid Yesus selamanya (14:16); mengajarkan dan mengingatkan para murid akan segala sesuatu yang telah diajarkan oleh Yesus (14:26); bersaksi tentang Yesus (15:26); menginsyafkan dunia akan dosa, kebenaran, dan penghakiman (16:8); dan memimpin para murid ke dalam segala kebenaran yang telah Ia dengar dari Yesus serta memuliakan Yesus (16:13-15).

Dalam terang bagian di atas, kita mendapati bahwa Roh Kudus tidak diutus untuk memberikan pewahyuan baru yang terpisah dari segala sesuatu yang telah

${ }^{11}$ Andreas J. Kostenberger, “The Sevent Johannine Sign: A Study in John's Christology,” BBR 5 (1995): 87-103. 
diajarkan Yesus atau bertentangan dengannya. Menurut ringkasan pengamatan Millard J. Erickson, peran Roh Kudus yang dibicarakan di sini berkenaan dengan menjelaskan kebenaran yang telah diajarkan Kristus serta mengerjakan iman, persuasi, dan keyakinan, tetapi bukan pewahyuan yang baru yang sebelumnya belum pernah disingkapkan. ${ }^{12}$ Ringkasan ini walau mayoritas mendapat dukungan dari teks di atas, namun gagal memperhitungkan pernyataan Yesus dalam Yohanes 14:25-26 dan 16:12-15. Roh Kudus bukan hanya mengingatkan akan segala sesuatu yang telah diajarkan Yesus, melainkan juga "mengajarkan segala sesuatu kepadamu" dan "memimpin kamu ke dalam seluruh kebenaran" yang belum diajarkan oleh Yesus. Kedua teks ini tidak kedengaran seperti sebuah penekanan mengenai iluminasi, tetapi pewahyuan yang baru. Pewahyuan yang baru yang dimaksudkan di sini adalah pengajaran-pengajaran yang diberikan oleh para rasul pasca tercurahnya Roh Kudus. ${ }^{13}$

Meski demikian, seperti yang sudah dikemukakan di atas, pewahyuan yang baru ini tidak terpisah dari pengajaran Yesus atau bertentangan dengannya. Yesus sendiri bahkan menyatakan bahwa Roh Kudus "tidak berkata-kata dari diri-Nya sendiri, tetapi segala sesuatu yang didengar-Nya itulah yang akan dikatakan-Nya dan Ia akan memberitakan kepadamu hal-hal yang akan datang. Ia akan memuliakan Aku, sebab Ia akan memberitakan kepadamu apa yang diterima-Nya daripada-Ku" (16:1314). ${ }^{14}$

Karena karya Roh Kudus di atas bukan merupakan karya yang terpisah dari pengajaran Kristus, maka dalam 1 Yohanes 5:20, pengenalan akan Yesus sebagai Allah yang benar dan yang memimpin kepada hidup kekal disebut sebagai karya Anak Allah, yaitu Yesus sendiri. Juga, perlu dicatat bahwa dalam bagian ini, pengertian serta pengenalan tersebut disebut sebagai sebuah "pemberian" (Yun. didomi). Melalui pelayanan Roh Kudus, umat Tuhan mendengar suara Yesus (bnd. Yoh. 10:3). Sementara itu, dalam 1 Yohanes 2:27, kita membaca sebuah nasihat yang menarik:

Sebab di dalam diri kamu tetap ada pengurapan yang telah kamu terima dari pada-Nya.

Karena itu tidak perlu kamu diajar oleh orang lain. Tetapi sebagaimana pengurapan-Nya mengajar kamu tentang segala sesuatu - dan pengajaran-Nya itu benar, tidak dusta - dan sebagaimana Ia dahulu telah mengajar kamu, demikianlah hendaknya kamu tetap tinggal di dalam Dia.

Tampaknya, klausa "Karena itu tidak perlu kamu diajar oleh orang lain," dianggap sebagai pembenaran untuk meniadakan atau setidaknya meminimalisasi studi yang serius terhadap Alkitab dalam rangka memahaminya dari para pengajar firman Tuhan (bnd. Kis. 13:1; 1Kor. 12:23; Ef. 4:11; 1Tim. 4:11). Misalnya, Raymond

12 Millard J. Erickson, Christian Theology (Epub version; $3^{\text {rd }}$ ed.; Grand Rapids, Michigan: Baker Academic, 2013).

13 Kata ganti orang kedua tunggal, "kamu" atau "kalian" dalam Yohanes 14-16 merujuk kepada para murid atau yang nanti disebut para rasul. Di dalam sejarah Kekristenan mula-mula, pasca kenaikan Yesus, pengajaran para rasul (apostolic teaching) adalah pengajaran-pengajaran otoritatif. Bnd. Robert L. Reymond, A New Systematic Theology of the Christian Faith (2 ${ }^{\text {nd }}$ edition - Revised and Updated; Nashville: Thomas Nelson, 1998), 61-62.

14 Teologi Ortodoks percaya bahwa pasca PB, tidak ada lagi pewahyuan yang baru (new revelation). Prinsip aksiomatis ini secara tidak langsung bertentangan dengan teologi rhema dan karunia nubuat yang marak di kalangan Pantekosta/Kharismatik. Jika Tuhan masih berbicara secara langsung melalui rhema bagi orang-orang Kristen dan orang-orang Kristen masa kini masih dapat bernubuat, itu haruslah sesuatu yang terkategori inspirasi. Dan jika itu merupakan inspirasi, maka itu pasti berotoritas mutlak setara dengan Alkitab. Maka, secara implikasi, teologi seperti ini menolak finalitas kanon Alkitab. 
E. Brown menyatakan bahwa penulis surat ini tampaknya melandasi tulisan di atas pada janji Yesus mengenai Parakletos (Roh Kudus; Yoh. 14:26; 16:13) kemudian menarik implikasi yang ekstrim dalam rangka menghadapi ajaran sesat yang beredar dalam komunitasnya dengan menyangkali kebutuhan akan para pengajar kebenaran. ${ }^{15}$

Harus diingat bahwa Yohanes menulis surat ini kepada audiens yang telah mengenal baik pengajaran-pengajaran Yesus $(2: 7,21)$. Tetapi, dari antara mereka, ada orang-orang yang mengajarkan ajaran-ajaran yang tidak sesuai dengan ajaran para rasul (2:18-19). Para pengajar sesat itu tampaknya mengklaim telah mendapatkan pengurapan Allah dan bahwa Roh Kudus telah mengimpartasikan bagi mereka kebenaran-kebenaran baru. ${ }^{16}$ Tetapi, Yohanes mendapati bahwa pengajaran mereka bertentangan dengan pengajaran para rasul. Itulah sebabnya dalam 1:1-4, Yohanes menegaskan kesaksian apostolik sebagai acuan untuk menerima pengajaran yang benar dan menolak pengajaran yang salah. Yohanes juga berbicara tentang "pengurapan" (Yun. khrisma) dari Yang Kudus (2:20) yang kemudian disebutkan lagi dalam ayat 27 yang merujuk kepada berdiamnya Roh Kudus di dalam diri setiap orang percaya saat mereka bertobat. ${ }^{17}$ Dalam konteks ini, yang dimaksudkan Yohanes dengan "Karena itu tidak perlu kamu diajar oleh orang lain," berarti bahwa mereka tidak memerlukan pengajaran dari para pengajar sesat tersebut, sebab mereka telah memiliki ajaran para rasul dan fakta bahwa Roh Allah berkarya di dalam diri mereka untuk mengingatkan mereka akan segala ajaran Kristus (bnd. Yer. 31:33; Yeh. 18:2). ${ }^{18}$ Karya Roh Kudus di sini bukan berkenaan dengan memberikan informasi-informasi berkenaan dengan isi pengajaran yang harus mereka percayai, melainkan meneguhkan otoritas pengajaran para rasul yang telah diajarkan kepada mereka.

Fakta bahwa Yohanes sendiri menulis surat ini untuk mengajar dan mengingatkan mereka akan pengajaran-pengajaran Kristus, secara pasti menolak tafsiran bahwa "Karena itu tidak perlu kamu diajar orang lain," berarti bahwa kita hanya memerlukan karya Roh Kudus tanpa berupaya untuk belajar tentang kebenaran dengan giat baik melalui studi pribadi maupun melalu pengajaran para pengajar kebenaran (1Kor. 12:28; Ef. 4:11; 2Tim. 1:11). Robert W. Yarbrough menandaskan, "Pernyataan Yohanes di sini tidak boleh dijadikan dasar untuk mengecilkan peran gembala-pengajar (Ef. 4:11) dalam Gereja mula-mula."19 Meski demikian, seperti yang dikemukakan oleh Roy B. Zuck, teks di atas mengingatkan kita bahwa pengertian akan Alkitab tidak hanya eksklusif dimiliki oleh kaum akademisi. Roh Kudus berkarya di dalam setiap orang Kristen untuk memahami Alkitab, meski itu juga tidak berarti bahwa studi yang intens dan serius terhadap Alkitab harus diabaikan saja. ${ }^{20}$

\footnotetext{
15 Raymond E. Brown, The Epistles of John (AB.; London: Geoffrey Chapman, 1983), 374-376; juga Georg Strecker, The Johannine Letters (Hermeneia; Minneapolis: Fortress, 1996), 76-77.

16 Karen H. Jobes, 1, 2, \& 3 John (Epub version; ZECNT; Grand Rapids, Michigan: Zondervan, 2014).

17 Ignace de la Poteria percaya bahwa "pengurapan" $(2: 20,27)$ bukan merujuk kepada Roh Kudus melainkan firman Allah. Tetapi, lih. Colin G. Kruse, The Letters of John (Epub version; PNTC: Grand Rapids, Michigan: Eerdmans, 2000).

18 Ian Howard Marshall, The Epistles of John (Epub version; NICNT; Grand Rapids, Michigan: Eerdmans, 1978). Argumen yang menolak pendapat Brown di atas dari perspektif rujukan kepada teks-teks PL tersebut, dapat dibaca dalam: D.A. Carson, "You Have No Need That Anyone Should Teach You' (1 John 2:27): An Old Testament Allusion that Determine Interpretation," 269-280.

${ }^{19}$ Robert W. Yarbrough, 1-3 John (BECNT; Grand Rapids, Michigan: Baker Academic, 2008), 166167.

${ }^{20}$ Roy B. Zuck, “The Role of Holy Spirit in Hermeneutics,” BSac., 141 (1984): 125.
} 


\section{Surat-surat Paulus}

Roma 1-2 berbicara tentang kondisi keberdosaan manusia yang begitu hebat mengikat dirinya. Manusia berdosa tanpa Kristus, meskipun kepada mereka Allah menyatakan kebenaran-Nya, namun mereka "menindas kebenaran dengan kelaliman" (1:18-19). Mereka "menggantikan kebenaran Allah dengan dusta" lalu hidup dalam penyembahan berhala (1:25). Hukum Taurat dan wahyu umum dimaksudkan sebagai penyingkapan Diri dan kehendak Allah, namun mereka menolaknya dan hidup di dalam kefasikan yang mendatangkan penghakiman atas mereka (2:1-29). Dalam 2 Korintus 4:4, Paulus menyebutkan bahwa "pikiran mereka telah dibutakan oleh ilah zaman ini, sehingga mereka tidak dapat melihat cahaya Injil tentang kemuliaan Kristus yang adalah gambaran Allah." Mereka adalah orang-orang yang tegar hatinya dan yang buta terhadap kebenaran (Rm. 11:7b-10).

Gambaran tentang kerusakan total akibat dosa di atas membuat kita memahami pernyataan Paulus dalam 1 Korintus 2:12-14,

Kita tidak menerima roh dunia, tetapi roh yang berasal dari Allah, supaya kita tahu, apa yang dikaruniakan Allah kepada kita. Dan karena kami menafsirkan hal-hal rohani kepada mereka yang mempunyai Roh, kami berkata-kata tentang karunia-karunia Allah dengan perkataan yang bukan diajarkan kepada kami oleh hikmat manusia, tetapi oleh Roh. Tetapi manusia duniawi tidak menerima apa yang berasal dari Roh Allah, karena hal itu baginya adalah suatu kebodohan; dan ia tidak dapat memahaminya, sebab hal itu hanya dapat dinilai secara rohani.

Ayat 12 menegaskan fakta pewahyuan yang diberikan oleh Roh Kudus (ay. 1011) bahkan Allah mengaruniakan Roh itu untuk berdiam di dalam umat-Nya (bnd. 1Kor. 3:16; 6:19). Penggunaan kata synkrino ("membandingkan," atau "menafsirkan") di bagian akhir ayat 13 membuatnya sulit untuk diterjemahkan. Namun, gagasan utamanya adalah bahwa hal-hal rohani hanya dapat dimengerti sepenuhnya melalui pertolongan Roh Allah. Ayat 14 dapat berarti orang-orang duniawi tidak dapat menerima (unwelcome) hal-hal rohani karena mereka tidak mengertinya (aposisi); atau orang-orang duniawi tidak dapat menerima hal-hal rohani dan mereka tidak dapat mengertinya (paralel sintetis). Saya percaya Daniel B. Wallace benar bahwa fungsi aposisi dari ayat 14 mengharuskan penggunaan kata Yunani oida. Namun dalam ayat ini, Paulus menggunakan kata Yunani ginosko maka kita harus melihatnya sebagai sebuah paralel sintetis. Jadi, yang Paulus maksudkan di sini adalah bahwa orang-orang tidak percaya memiliki masalah penerimaan terhadap kebenaran (volitional problem) dan memiliki masalah pengertian intelektual terhadap kebenaran (intellectual problem) karena dosa mendistorsi seluruh keberadaan mereka. ${ }^{21}$ Pengertian seperti ini konsisten dengan teologi Paulus mengenai dosa dan juga ajaran Kitab-kitab Injil mengenai ketegartengkukan Israel seperti yang sudah saya bahas di atas.

Dalam Mazmur 119:18, pemazmur berdoa agar matanya (LXX: tous oftalmos mou) disingkapkan untuk melihat keajaiban Taurat Tuhan. Dalam Efesus 1:18, Paulus berdoa agar mata hati (Yun. tous oftalmos tes kardias; bnd. Mzm. 13:4; 19:9) jemaat di Efesus diberi iluminasi (penerangan) untuk mengerti (Yun. oida) kekayaan kemuliaan yang terkandung di dalam ketetapan Allah yang berdaulat yang telah memilih mereka yang menjadikan mereka berpengharapan. Sebuah pengharapan yang tersauh dalam

${ }^{21}$ Daniel B. Wallace, "The Holy Spirit and Hermeneutics," in https://bible.org/article/holy-spiritand-hermeneutics, diakses tanggal 12 Mei 2016. 
kehebatan kuasa Injil Kristus yang telah menjadikan mereka sebagai tubuh dan Kristus sebagai Kepala (1:19-23). Paulus mendoakan demikian, karena dulu sebagai orang-orang yang belum percaya pengertian mereka gelap (4:18) dan mereka hidup di dalam kegelapan (5:8). Namun setelah bertobat, mata hati mereka telah diterangi dan kini Paulus berdoa agar pikiran mereka berpaut hanya kepada anugerah Allah. ${ }^{22}$ Paulus menggunakan ungkapan senada dalam 2 Korintus 4:6 untuk berbicara mengenai cahaya ilahi yang memberikan iluminasi yang menerangi hati dan pengertian kita untuk mengerti tentang kemuliaan Allah di dalam Kristus. ${ }^{23}$ Juga dalam bagian-bagian lain, Paulus mendoakan agar para pembaca suratnya mendapatkan iluminasi sehingga mereka dapat bertumbuh dalam pemahaman dan pengetahuan akan kebenaran (1Kor. 2:2; Flp. 1:9-11; Kol. 1:9-13).

\section{Surat Ibrani}

Sama seperti 2 Korintus 4:6 dan Efesus 1:18, Surat Ibrani mencatat juga mengenai penerangan bagi hati untuk menerima kebenaran dalam pasal 6:4 dan 10:32.

Ibrani 6:4-6 merupakan teks yang perdebatan mengenai signfikansinya tidak konklusif hingga sekarang. Teks ini didiskusikan dalam kaitan dengan apakah orang yang sudah lahir baru (orang Kristen sejati) dapat murtad kemudian kehilangan keselamatannya? Karena bukan tujuan saya untuk membahas isu ini, saya hanya ingin menegaskan bahwa saya tidak memandang teks ini sebagai pendukung untuk pandangan bahwa orang-orang yang sudah lahir baru dapat kehilangan keselamatan mereka. Kata "diterangi" (Yun. fotidzo) dalam teks ini pada dirinya sendiri tidak mengandung gagasan mengenai lahir baru (Luk. 11:36; Yoh. 1:9; 1Kor. 4:5; Ef. 1:18; Ibr. 10:32). Meski bentuk pasif yang digunakan di sini (Yun. fotisthentas) berarti bahwa orang yang bersangkutan pernah "diterangi" oleh Allah atau oleh firman-Nya. Penggunaan kata ini di sini semata-mata berarti bahwa orang yang dimaksudkan itu pernah diajari dengan kebenaran. ${ }^{24}$

Penggunaan kata yang sama (Yun. fotidzo) dalam Ibrani 10:32, meskipun digunakan untuk orang-orang percaya, namun kata itu sendiri tidak mengandung arti lahir baru. Kata itu digunakan dalam teks ini sejajar dengan penggunaan klausa "memperoleh pengetahuan kebenaran" dalam 10:26. ${ }^{25}$

Jadi, dua kali penggunaan kata fotidzo dalam Surat Ibrani mengindikasikan bahwa orang-orang yang dibicarakan itu pernah diajar dengan kebenaran firman Tuhan. Menarik di sini adalah bahwa di samping orang yang sudah percaya harus mendapatkan pengajaran tentang pengetahuan akan kebenaran $(10: 26,32)$, namun pengetahuan akan kebenaran itu sendiri bukan merupakan bukti satu-satunya untuk diselamatkan (6:4). Mereka yang memiliki pengetahuan akan firman Tuhan namun murtad, membuktikan bahwa sejak awal, mereka bukanlah milik Tuhan. Grudem

22 "Hati" merujuk kepada keseluruhan aspek manusia (pusat dan sumber kehidupan fisik - Mzm. 101:5; 103:15; Kis. 14:17; kehidupan batiniah, yakni emosi dan perasaan - Rm. 1:24; 9:2; 2Kor. 2:4; kehendak - 2Kor. 9:7; dan pikiran Ef. 1:18; 2Kor. 4:6).

23 F.F. Bruce, The Epistles to the Colossians, to Philemon, and to the Ephesians (Epub version; NICNT: Grand Rapids, Michigan: Eerdmans, 1984).

${ }^{24}$ Saya mengikuti argumen yang dikemukakan, mis. R. Bruce Compton, "Persevering and Falling Away: A Reexamination of Hebrews 6:4-6," DBSJ 1 (Spring 1996): 146-148; Wayne Grudem, "Perseverance of the Saints: A Case Study of Hebrews 6:4-6 and the Other Warning Passages in Hebrews," in Thomas R. Schreiner and Bruce Ware (eds.), The Grace of God and the Bondage of Will (Grand Rapids, Michigan: Baker, 1995), 1.133-182.

25 Compton, "Persevering and Falling Away: A Reexamination of Hebrews 6:4-6," 147. 
menyatakan, "Pastinya pengertian intelektual akan fakta-fakta Injil merupakan langkah penting menuju iman yang menyelamatkan, tetapi itu tidak pada dirinya sendiri membentuk kepercayaan pribadi akan Kristus yang sangat esensial bagi iman."26

Setelah mengamati sejumlah teks penting di atas, saya menyimpulkan beberapa pokok penekanan: Pertama, Kondisi keberdosaan manusia membuatnya impoten untuk mengerti kebenaran serta signifikansinya. Mereka dapat memiliki pengetahuan intelektual akan kebenaran (Ibr. 6:4) namun kebenaran itu dianggap sebagai kebodohan (1Kor. 2:14) dan diputarbalikkan menjadi kebinasaan bagi mereka (Rm. 1-2). Dosa mengikat mereka sedemikian rupa sehingga mereka menolak Kristus dan penolakan mereka itu diidentifikasi sebagai kondisi "tidak diberi karunia untuk mengerti” akan kebenaran (Mat. 13:13-15; Mrk. 4:12; Luk. 8:4-15; Yoh. 12:40). Dalam konteks ini, kita tidak dapat menyimpulkan bahwa mereka tidak mengerti secara intelektual sama sekali. Sebaliknya, teks-teks ini mengasumsikan bahwa mereka memiliki pengertian intelektual akan kebenaran dalam tahap tertentu, namun mereka "menindas kebenaran" itu (Rm. 1:18-19). Jadi, ketidakmengertian mereka akan kebenaran, bukan terutama persoalan intelektual saja, melainkan keseluruhan sikap mereka terhadap kebenaran itu sendiri.

Kedua, Kondisi di atas mengharuskan adanya iluminasi Roh Kudus yang "menginsyafkan" mereka akan dosa dan penghakiman atas dosa serta kesadaran kebutuhan untuk diselamatkan oleh Kristus (Yoh. 14-16). Ketiga, Iluminasi juga diperlukan untuk mengerti firman Tuhan secara kognitif yang berarti memiliki pemahaman yang utuh akan firman Tuhan (2Kor. 4:6; Ef. 1:18). Iluminasi Roh Kudus memampukan setiap orang percaya untuk memahami firman Tuhan (1Kor. 2:12-14; 1Yoh. 2:27), namun bukan pengganti untuk studi yang terus menerus akan firman Tuhan karena iluminasi itu sendiri bukan merupakan sumber informasi terpisah dari Alkitab, melainkan karya Roh Kudus yang memberikan kemampuan untuk mengerti firman Tuhan secara benar, menerima serta mempercayainya sebagai kebenaran (Mzm. 1:2; 1Kor. 12:28; Ef. 4:11; 2Tim. 1:11; bnd. Luk. 1:1-4; 2Tim. 2:15). Iluminasi Roh Kudus mengerjakan kesukaan untuk membaca dan menyelidiki firman Tuhan (Mzm. 1:2; 19; 119).

Harus senantiasa diingat bahwa sasaran utama dari eksegesis bukan sekadar untuk menghasilkan tafsiran yang sedapat mungkin akurat (2Tim. 2:15), melainkan transformasi bagi sang ekseget itu sendiri dan juga orang-orang yang kepada mereka ia membagikan hasil eksegesisnya. Maka dalam rangka memetakan prinsip-prinsip di atas secara jelas, saya akan mendiskusikan mengenai pandangan Erickson dan Fuller mengenai iluminasi Roh Kudus di bawah ini.

\section{Diskusi Fuller dan Erickson}

Berikut ini saya akan mengemukakan inti diskusi antara Daniel P. Fuller dan Millard J. Erickson mengenai hubungan iluminasi dengan tugas eksegesis.

\section{Pandangan Fuller}

Pandangan Fuller mengenai iluminasi dan eksegesis berhubungan dengan dua pasang topik detail.

${ }^{26}$ Grudem, "Perseverance of the Saints: A Case Study of Hebrews 6:4-6 and the Other Warning Passages in Hebrews," 145. 
Pertama, volisi (kehendak; volitional) dan nosi (pengertian; notional). Dalam tulisannya yang berjudul: The Holy Spirit's Role in Biblical Interpretation, Fuller menyatakan bahwa setiap orang (termasuk agnostik dan atheis) dapat secara tepat dan akurat memahami Alkitab bila mereka memiliki ketrampilan eksegesis dan menggunakannya secara baik saat menafsirkan Alkitab. Menurutnya, pelaksanaan tugas eksegesis tidak berurusan dengan iluminasi Roh Kudus. Iluminasi Roh Kudus tidak dibutuhkan untuk mencapai pemahaman kognitif akan Alkitab. ${ }^{27}$ Intinya, dalam aspek pemahaman (notional), semua orang tanpa kecuali dapat memahami Alkitab secara akurat dengan menggunakan ketrampilan eksegetisnya.

Lalu, kapankah iluminasi terjadi dan dalam hubungan dengan apa? Menurut Fuller, iluminasi terjadi untuk memampukan seseorang menerima kesimpulan eksegetis yang telah dipahaminya. Untuk menghendaki dan menerima kebenaran Alkitab, iluminasi diperlukan. Pada tahap ini Roh Kudus mengatasi keangkuhan hati seseorang yang menghalanginya untuk menerima kebenaran Alkitab. Roh Kudus mengaruniai seseorang untuk mengasihi firman Tuhan sehingga ia dapat mengaplikasikannya dalam kehidupannya. ${ }^{28}$ Jadi, bagi Fuller iluminasi tidak berhubungan dengan aspek pemahaman, tetapi penerimaan akan pemahaman tersebut.

Kedua, metode eksegesis dan Roh Kudus. Ada segolongan orang Kristen yang berpandangan bahwa pemahaman yang benar akan Alkitab semata-mata bergantung atas doa untuk mendapatkan iluminasi Roh Kudus. Tidak perlu menerapkan prinsip eksegetis sama sekali. Mereka berseru:

Berdoalah untuk mendapatkan iluminasi Roh Kudus agar mampu memahami lebih dalam mengenai apa yang telah tertulis.... Semakin banyak engkau berdoa ... semakin banyak wawasan dari Roh Kudus dianugerahkan kepadamu. ${ }^{29}$

Untuk menolak pneumatic-exegesis atau spiritual-exegesis ${ }^{30}$ tersebut, Fuller mengemukakan pengamatannya mengenai penggunaan pendekatan ini dalam sejarah Gereja. $^{31}$ Menurut Fuller, pendekatan spiritualis ini selalu menghasilkan tafsiran alegoris. Itulah sebabnya, ia menandaskan bahwa ketimbang bergantung atas iluminasi Roh Kudus, seseorang harus bergantung atas ketrampilan eksegetisnya. ${ }^{32}$ Bagi Fuller, metode eksegesis memegang peranan utama. Tidak ada peran Roh Kudus sama sekali dalam urusan memahami Alkitab.

27 Daniel P. Fuller, “The Holy Spirit's Role in Biblical Interpretation," in Scripture, Tradition, and Interpretation, eds. W. Ward Gasque \& William Sanford LaSor (Grand Rapids, Michigan: Eerdmans, 1978), 192.

${ }^{28}$ Beberapa teolog lain yang menganut pandangan ini, antara lain: William Larkin, Culture and Biblical Hermeneutics (Grand Rapids, Michigan: Baker, 1988), 289; Roy B. Zuck, "The Role of the Holy Spirit in Hermenutics," Bibliotheca Sacra 141 (April-June, 1984), 123-124; sebelumnya Zuck sudah mengemukakan pandangan ini secara luas dalam: Teaching with Spiritual Power (Grand Rapids, Michigan: Kregel, 1993).

${ }^{29}$ Bruce H. Wilkinson, The 7 Laws of the Learner (Sisters, OR.: Multnomah, 1992), 143.

30 Pneumatic-exegesis atau spiritual-exegesis adalah istilah yang digunakan Gerrit Berkouwer untuk menyebut kecenderungan di atas (Holy Scripture (Grand Rapids, Michigan: Eerdmans, 1975), 111; Rene Padilla menyebut pendekatan ini: intuitive model, lih. "The Interpreted Word: Reflections on Contextual Hermeneutics," in A Guide to Contemporary Hermeneutics: Major Trends in Biblical Interpretation, ed. Donald K. McKim (Grand Rapids, Michigan: Eerdmans, 1986), 297-298. Lih. juga ulasan dalam Bab 7.

31 Perlawanan terhadap pendekatan spirtualis di atas juga dilakukan oleh: Walter C. Kaiser, "Evangelical Hermeneutics: Restatement, Advance or Retreat from the Reformation?" in Concordia Theological Quarterly 46 (April-July, 1982): 168.

32 Fuller, “The Holy Spirit's Role in Biblical Interpretation,” 189-190, 192. 
Memahami Alkitab, demikian menurut Fuller, sepenuhnya merupakan masalah kognitif. Pada aspek ini, iluminasi Roh Kudus tidak diperlukan. Iluminasi itu terjadi pada saat seseorang menerima atau mengakui pemahaman yang telah dicapainya sebagai kebenaran. Pandangan ini dianut juga oleh Grant R. Osborne. Menurut Osborne, meskipun iluminasi Roh Kudus berurusan dengan aspek pemahaman kognitif akan firman Tuhan, namun itu tidak menjamin hasil penafsiran yang benar. Roh Kudus tidak memberikan informasi langsung mengenai makna teks yang ditafsirkan. Itulah sebabnya, kita harus menggunakan kapasitas rasional kita serta menerapkan perangkat-perangkat eksegetis untuk memahami kebenaran. Dalam kategori ini, orang-orang tidak percaya pun dapat melakukannya. Menurutnya, teksteks semisal 1 Korintus 2:14 dan 2 Korintus 4:4 tidak menafikan kemampuan para penafsir non Kristen untuk mengerti Alkitab secara rasional. Yang tidak dapat dimiliki oleh para penafsir non Kristen adalah penerimaan terhadap implikaiimplikasi dari kebenaran Alkitab. ${ }^{33}$ Meski demikian, Osborne menegaskan keharusan iluminasi dengan menyatakan, "Kita harus bergantung atas Allah dan bukan hanya atas prinsip-prinsip hermeneutis ketika mempelajari Alkitab."34

\section{Pandangan Erickson}

Dari aspek: eksegesis, biblika, teologis, dan logika, Erickson melawan posisi Fuller dengan menautkan iluminasi pada masalah persepsi yang diperoleh dari tugas eksegetis. Roh Kudus memampukan seseorang untuk memahami Alkitab. Bagi Erickson, orang-orang tidak percaya tidak mungkin bisa memahami Alkitab secara akurat karena efek dosa yang menjadikan pemikiran mereka bias terhadap firman Tuhan. Hanya Roh Kudus yang dapat mengatasi efek dosa dalam aspek pemahaman kognitif. ${ }^{35}$

Mengenai kritik Fuller terhadap pendekatan spiritualis, Erickson menuduh Fuller bereaksi berlebihan sehingga ia membuang peran Roh Kudus sama sekali dalam proses eksegesis. Bagi Erickson, pandangan Fuller adalah sebuah disjungsi palsu (false disjunction). Seakan-akan orang harus memilih salah satu di antara iluminasi atau pendekatan eksegetis; antara pemahaman atau pencerahan dari Roh Kudus. Erickson menekankan peran Roh Kudus baik dalam aspek pemahaman maupun dalam aspek pengalaman (penerimaan akan kebenaran). Kedua aspek ini bersifat saling melengkapi (complementary), bukan bertolak belakang (antithetical). Bagi Erickson, ketrampilan eksegesis tidak meniadakan kebutuhan akan iluminasi. Demikian pula sebaliknya, kebutuhan akan iluminasi tidak meniadakan urgensi ketrampilan eksegesis. ${ }^{36}$

\section{Evaluasi}

${ }^{33}$ Grant R. Osborne, The Hermeneutical Spiral: A Comprehensive Introduction to Biblical Interpretation (Revised and Expanded; Downers Grove, Illinois: IVP Academic, 2006), 435-437.

34 Ibid, 22.

35 Erickson, Christian Theology (Epub version); Millard J. Erickson, Evangelical Interpretation: Perspectives on Hermeneutical Issues (Grand Rapids, Michigan: Baker, 1993), 33-54; bab dua dari buku ini secara khusus ditulis untuk melawan pandangan Fuller.

${ }^{36}$ Erickson, Evangelical Interpretation, 47, 54. Para penulis lainnya yang sepakat dengan Erickson, antara lain: Donald Bloesch, Christian Foundations: A Theology of Word and Spirit, Vol. 1 (Downers Grove, Illinois: InterVarsity, 1992), 59; Arthur Pink, The Holy Spirit (Grand Rapids, Michigan: Baker, 1970), 63; Clark Pinnock, "The Role of the Spirit in Interpretation," Journal of the Evangelical Theological Society 36 (Desember, 1993): 491-497. 
Meski secara khusus perhatian saya di atas terpusat pada dua pandangan mengenai hubungan iluminasi dan eksegesis, namun di dalamnya sudah disinggung satu pandangan lain, yaitu pendekatan spiritualis.

Hal pertama yang perlu dicatat dari diskusi di atas adalah poin-poin yang disepakati bersama oleh Fuller dan Erickson: (1) Fuller dan Erickson sepakat bahwa inspirasi Alkitab sudah final. Yang diperlukan sesudah Alkitab selesai ditulis bukan lagi inspirasi, melainkan iluminasi Roh Kudus. (2) Fuller dan Erickson mengaminkan bahwa seseorang tidak akan dapat menerima kebenaran Alkitab tanpa diiluminasikan oleh Roh Kudus. (3) Fuller dan Erickson sama-sama menolak pendekatan spiritualis, walau dalam aspek tertentu Erickson mengakomodasinya. (4) Fuller dan Erickson sependapat bahwa metode eksegesis memegang peranan penting dalam hal pemahaman yang akurat akan kebenaran Alkitab.

Selanjutnya, kedua teolog ini berbeda dalam hal berikut: (1) Erickson percaya bahwa pemahaman yang akurat serta penerimaan akan firman Tuhan hanya dapat terjadi melalui iluminasi Roh Kudus, sementara Fuller menolak hal ini sebagai reaksi terhadap para penganut model spiritualis. Ia hanya menghubungkan iluminasi dengan masalah penerimaan akan firman Tuhan. (2) Fuller tidak memperhitungkan efek dosa terhadap pemahaman akan kebenaran. Sebaliknya, Erickson percaya bahwa efek dosa terhadap pemahaman akan kebenaran merupakan alasan mengapa harus ada ilumasi yang memungkinkan adanya pengertian yang akurat akan Alkitab. (3) Fuller percaya bahwa semua orang tanpa kecuali dapat mengerti Alkitab secara akurat dengan menggunakan ketrampilan eksegetisnya. Erickson membatasi hal ini hanya bagi mereka yang telah dilahirkan kembali. (4) Fuller sama sekali menolak pendekatan spiritualis dalam memahami Alkitab. Erickson, sebagaimana para penganut spiritualis, berdoa agar diiluminasikan oleh Roh Kudus untuk memahami Alkitab. Hanya saja, Erickson menolak sikap ekstrim kaum spiritualis bahwa untuk memahami Alkitab seseorang hanya memerlukan doa untuk memohon iluminasi. Erickson percaya bahwa doa untuk mendapatkan iluminasi tidak meniadakan ketrampilan eksegesis.

Menyimak titik temu dan titik beda antara Fuller dan Erickson di atas, berikut ini saya akan mengemukakan sejumlah argumentasi yang menunjukkan posisi saya dalam hubungan dengan topik ini.

Saya sependapat dengan Erickson bahwa Fuller (juga Osborne) mengabaikan atau setidaknya mengecilkan distorsi (efek yang bersifat merusak) dosa terhadap keseluruhan aspek kemanusiaan kita. Dosa bukan hanya memperbudak hati sebagai pusat kepribadian yang di dalamnya terdapat kehendak dan nafsu-nafsu jahat, melainkan juga mengakibatkan pemikiran manusia menjadi bias terhadap kebenaran. Tetapi, saya melihat bahwa pandangan Fuller (dan Osborne) tetap memiliki poin valid yang tidak dapat diabaikan. Perihal manusia telah terdistorsi sedemikian rupa oleh dosa, itu tidak menjadikan kemampuan logika mereka menjadi tidak berfungsi sama sekali. Kebenaran, tentu saja, memiliki aspek intelektual di dalamnya, maka kita tidak dapat menyatakan bahwa secara intelektual, mereka yang belum percaya tidak memiliki pengertian apa pun ketika mereka membaca Alkitab. Ian Howard Marshall memperlihatkan kenyataan menarik ini: 
Tidak diragukan banyak wawasan yang benar dan valid mengenai makna Alkitab telah dikemukakan oleh para sarjana yang bukan Kristen, dan para sarjana Kristen menerima wawasan ini dengan penuh ucapan syukur. ${ }^{37}$

Dalam pengertian tertentu, orang-orang percaya dapat menyelidiki aspek kesejarahan dan kebahasaan Alkitab dan menangkap ide yang fragmental tentang kebenaran. Tetapi, mereka akan selalu sampai pada kesimpulan yang bias akan maksud Alkitab secara utuh. Karena memang, sebagaimana literatur-literatur kuno lainnya, Alkitab pun (dalam tahap tertentu) mesti dipelajari dari aspek ini. Tetapi, natur Alkitab melampui sifat kesejarahan dan kebahasaannya. Alkitab adalah firman Tuhan yang memiliki dimensi supernatural dan spiritual. Untuk memahami Alkitab, seseorang tidak saja memerlukan perangkat-perangkat saintifik, linguistik, sejarah, dan filosofis. Pengertian yang utuh akan kebenaran dan mendatangkan manfaat haruslah diinisiasi oleh Roh Kudus yang telah mewahyukan firman Tuhan (2Tim. 3:16), serta yang terus tuntun oleh-Nya. Karena itu, Rene Pache menulis, "Sebuah kitab yang diinspirasikan oleh Roh Kudus hanya dapat dipahami melalui intervensi dari Roh Kudus itu sendiri." 38 Pache juga mengutip penegasan-penegasan mengenai hal ini dari Luther, Zwingli, dan Calvin. ${ }^{39}$

Poin penegasan saya adalah bahwa iluminasi itu harus terjadi pada saat seseorang melakukan eksegesis untuk dapat memahami maksud yang seutuhnya dari Alkitab. Tanpa iluminasi, pemahaman yang dicapai seorang ekseget hanya bersifat fragmental dan ia akan menyimpulkannya secara bias kemudian menolaknya sebagai kebodohan. Dengan demikian, saya percaya kelemahan dari Fuller dan Erickson dalam diskusi di atas adalah bahwa mereka meletakkan isu ini dalam kategori yang salah (kategori either/or) seakan-akan problem iluminasi itu adalah problem intelektual saja atau problem penerimaan terhadap kebenaran saja. Dalam eksegesis saya terhadap teks-teks di atas, kategori dikotomis seperti ini tidak mendapatkan dukungan. Orang-orang percaya sekaligus memiliki masalah volisi maupun kognisi ketika itu berurusan dengan pemahaman terhadap firman Allah. Di sisi lain, di dalam diri orang-orang percaya, Roh Kudus bekerja pada aspek emosi (kesukaan, kesenangan, dan kekaguman akan firman Tuhan), aspek kognitif (mencerahkan pemikiran mereka untuk memahami kebenaran) dan aspek kehendak (mengerjakan iman di dalam diri mereka untuk percaya kepada firman Tuhan).

Dalam hubungan dengan pemahaman eksegetis dan penerimaan akan kebenaran yang dipahami itu, Pache menulis tentang sifat dari iluminasi Roh Kudus. Pache menyatakan bahwa iluminasi Roh Kudus bersifat tetap (permanent) dan bersifat meningkat (increasing). Sifat tetap iluminasi berhubungan dengan karya Roh Kudus yang memampukan seorang yang belum percaya untuk memberi respons positif terhadap kebenaran dan olehnya orang tersebut diselamatkan. Sifat meningkat dari iluminasi adalah karya Roh Kudus yang terus-menerus memimpin orang percaya "kepada seluruh kebenaran" (Yoh. 16:13). ${ }^{40}$ John Owen pun menulis mengenai ide ini, walau dengan sebutan yang berbeda. Owen menyebutnya "salvific ilumination" dan "interpretive ilumination". Yang pertama berhubungan dengan karya Roh Kudus yang

37 Ian Howard Marshall, “The Holy Spirit's Role in Biblical Interpretation,” in Roy B. Zuck (ed.), Rightly Divided: Readings in Biblical Hermeneutics (Grand Rapids, Michigan: Kregel Academic, 1996), 66.

38 Rene Pache, The Inspiration and Authority of Scripture, trans. Helen I. Needham (Chicago: Moody Press,1977), 199.

39 Ibid, 199-200.

40 Ibid, 199-200. 
menyelamatkan. Yang kedua berhubungan dengan karya Roh Kudus yang membukakan pemahaman akan firman Tuhan. ${ }^{41}$

Jelas bahwa pemahaman yang utuh akan kebenaran hanya dapat dimiliki oleh orang percaya, yakni pemahaman yang merupakan bagian dari ketaatan iman (Rm. 1:5). ${ }^{42} \mathrm{Hal}$ ini tidak mungkin terjadi pada orang non percaya. Roh Kudus sebagai Sang Pewahyu yang dapat memberikan pencerahan kepada seseorang untuk memahami Alkitab secara utuh. Dan ini hanya dapat terjadi, bila terlebih dahulu Roh Kudus telah menghidupkan orang tersebut untuk berjumpa dengan Kristus, Sang Juruselamat (Yoh. 3:3; 15:26).

\section{Kesimpulan: Iluminasi dan Doa}

Selanjutnya, saya perlu mengulas tentang sarana anugerah yang berperan vital dalam menolong orang percaya memperoleh iluminasi Roh Kudus, yaitu doa. Dalam ulasannya mengenai hal ini, Owen mengharuskan setiap orang percaya yang membaca Alkitab untuk berdoa memohon penerangan dari Roh Kudus. Menurutnya, melalui doa segala sikap negatif terhadap Alkitab akan terhalau. ${ }^{43}$ Sebagai gantinya, Allah menganugerahkan kerendahhatian dan kualitas-kualitas rohani lainnya. ${ }^{44}$ Doa membuat seorang penafsir menjadi lebih terbuka untuk belajar dari Allah melalui Alkitab (teachable). ${ }^{45}$

Saya tidak sama yakinnya dengan Owen bahwa doa akan membereskan segala ketidakberesan dalam diri orang percaya. Alkitab memang membicarakan tentang doa sebagai sarana anugerah yang Tuhan sediakan bagi umat-Nya untuk berkomunikasi dengan Dia. Tetapi, harus selalu diingat bahwa doa yang dipanjatkan orang percaya tetap merupakan doa yang tidak sempurna, bahkan si pendoanya pun merupakan pribadi yang tidak sempurna. Lagi pula, bila doa sedemikian efektif dan berkhasiatnya untuk membereskan segala kebobrokkan yang ada dalam diri orang percaya, bukankah kita tidak lagi membutuhkan apa pun selain doa? Bukankah dengan doa, bila kita menyetujui gagasan Owen, kita sudah dapat menempuh hidup yang berkenan kepada Tuhan? Suatu gagasan yang sangat ambivalen dengan keyakinan Owen mengenai pentingnya iluminasi dan eksegesis Alkitab. Meski demikian, gagasan Owen mengenai keharusan berdoa untuk memperoleh iluminasi, memang harus diaminkan (Mzm. 119:18; Ef. 1:18; 1Kor. 2:2; Flp. 1:9-11; Kol. 1:9-13). Tanpa doa, seseorang tidak dapat mengklaim mendapatkan pencerahan dari Roh Kudus!

Saya ingin kembali kepada gagasan Fuller bahwa orang tidak percaya pun dapat memahami Alkitab secara akurat walau mereka kemudian menolaknya sebagai kebenaran. Ulasan tentang doa secara implikatif mengecilkan kekuatan klaim tersebut.

Mengakhiri ulasan ini, aspek penting yang perlu saya tandaskan kembali adalah bahwa Alkitab, firman Tuhan, hanya dapat dipahami dan diterima kebenarannya, bila Pewahyunya, yaitu Roh Kudus berkarya memberikan iluminasi di dalam seluruh

${ }^{41}$ John Owen, The Works of John Owen, ed. William Goold (Reprinted edition; Edinburgh: Banner of Truth, 1965-1968), 4:161.

${ }^{42}$ LAI-ITB menerjemahkan frasa Yunani hupakoen pisteos menjadi "percaya dan taat". Seharusnya diterjemahkan "ketaatan iman," yaitu ketaatan yang lahir dari iman atau bahwa ketaatan merupakan buah dari iman.

43 Owen, The Works of John Owen, 4:202.

${ }^{44}$ Ibid, 4:154, 160, 179, 183, 185, 186.

45 Ibid. 
prosesnya. Dan untuk itu, belas kasihan-Nya perlu dicari dengan rendah hati melalui doa.

\section{Daftar Pustaka}

Christian Theology. Epub version; 3rd ed.; Grand Rapids, Michigan: Baker Academic, 2013.

. "Logos dan Rhema menurut David Yonggi Cho: Teologi yang Sembrono dan Berbahaya," dalam Kembong Mallisa', dkk. (eds.), Berjuanglah Sampai Akhir: Kumpulan Tulisan dalam Rangka Dies Natalis SETIA ke-30. Jakarta: Delima, 2017.

Berkouwer, Gerrit. Holy Scripture. Grand Rapids, Michigan: Eerdmans, 1975

Bloesch, Donald, Christian Foundations: A Theology of Word and Spirit, Vol. 1. Downers Grove, Illinois: InterVarsity, 1992.

Brown. Raymond E., The Epistles of John. AB.; London: Geoffrey Chapman, 1983.

Bruce, F.F. The Epistles to the Colossians, to Philemon, and to the Ephesians. Epub version; NICNT: Grand Rapids, Michigan: Eerdmans, 1984.

Carson. D.A. "You Have No Need That Anyone Should Teach You' (1 John 2:27): An Old Testament Allusion that Determine Interpretation,"

Colin G. Kruse, The Letters of John. Epub version; PNTC: Grand Rapids, Michigan: Eerdmans, 2000.

Compton. R. Bruce, "Persevering and Falling Away: A Reexamination of Hebrews 6:46," DBSJ 1 (Spring 1996): 146-148.

Erickson, Millard J, Evangelical Interpretation: Perspectives on Hermeneutical Issues. Grand Rapids, Michigan: Baker, 1993.

Evans, Craig A. To See and Not Perceive: Isaiah 6.9-10 in Early Jewish and Christian Interpretation. JSOT Supp. 64; Sheffield: JOST Press, 1989.

Fuller. Daniel P, "The Holy Spirit's Role in Biblical Interpretation," in Scripture, Tradition, and Interpretation, eds. W. Ward Gasque \& William Sanford LaSor. Grand Rapids, Michigan: Eerdmans, 1978.

Gruber, Mayer I. Rashi's Commentary on Psalms. Leiden-Boston: Brill, 2004

Grudem, Wayne, "Perseverance of the Saints: A Case Study of Hebrews 6:4-6 and the Other Warning Passages in Hebrews," in Thomas R. Schreiner and Bruce Ware (eds.), The Grace of God and the Bondage of Will. Grand Rapids, Michigan: Baker, 1995.

Jobes, Karen H., 1, 2, \& 3 John. Epub version; ZECNT; Grand Rapids, Michigan: Zondervan, 2014.

Kaiser, Walter C. "Evangelical Hermeneutics: Restatement, Advance or Retreat from the Reformation?" in Concordia Theological Quarterly 46 April-July, 1982.

Kostenberger, Andreas J. "The Sevent Johannine Sign: A Study in John's Christology," BBR 5 (1995): 87-103.

Larkin. William, Culture and Biblical Hermeneutics. Grand Rapids, Michigan: Baker, 1988.

Longman III Tremper, Psalms: Introduction and Commentary. Epub version; TOTC; Nottingham: IVP, 2014. 
Marshall, Ian Howard, "The Holy Spirit's Role in Biblical Interpretation," in Roy B. Zuck (ed.), Rightly Divided: Readings in Biblical Hermeneutics. Grand Rapids, Michigan: Kregel Academic, 1996.

Marshall, Ian Howard, The Epistles of John Epub version; NICNT; Grand Rapids, Michigan: Eerdmans, 1978.

Nggadas. Deky Hidnas Yan, "Hubungan Kedaulatan Allah dan Tanggung Jawab Manusia: Suatu Studi Eksegesis Matius 13:10-17," dalam Jurnal Amanat Agung Volume 4, Nomor 1 (Juni, 2008).

Osborne, Grant R. The Hermeneutical Spiral: A Comprehensive Introduction to Biblical Interpretation. Revised and Expanded; Downers Grove, Illinois: IVP Academic, 2006.

Owen, John Owen, The Works of John Owen, ed. William Goold. Reprinted edition; Edinburgh: Banner of Truth, 1965-1968.

Pache, Rene, The Inspiration and Authority of Scripture. Trans. Helen I. Needham. Chicago: Moody Press, 1977.

Pink. Arthur, The Holy Spirit. Grand Rapids, Michigan: Baker, 1970.

Pinnock, Clark, "The Role of the Spirit in Interpretation," Journal of the Evangelical Theological Society 36 (Desember, 1993).

Rene Padilla, "The Interpreted Word: Reflections on Contextual Hermeneutics," in $A$ Guide to Contemporary Hermeneutics: Major Trends in Biblical Interpretation. ed. Donald K. McKim, Grand Rapids, Michigan: Eerdmans, 1986.

Reymond, Robert L. A New Systematic Theology of the Christian Faith $2^{\text {nd }}$ edition Revised and Updated; Nashville: Thomas Nelson, 1998.

Silalahi. Djaka Christianto, Rhema: Istilah Baru untuk Kekuatan Batin? Yogyakarta: Andi, 2001.

Strecker, Georg. The Johannine Letters. Hermeneia; Minneapolis: Fortress, 1996

Towns, Elmer. Foundational Doctrines of the Faith. Elkton, MD.: Ephesians Four Ministries, 2000.

Wallace, Daniel B. "The Holy Spirit and Hermeneutics," in https://bible.org/article/holy-spirit-and-hermeneutics, diakses tanggal $12 \mathrm{Mei}$ 2016.

Waltke, Bruce K. and Charles Yu, An Introduction to the Old Testament: An Exegetical, Canonical, and Thematic Approach. Grand Rapids, Michigan: Zondervan, 2007

Wilkinson. Bruce H, The 7 Laws of the Learner. Sisters, OR.: Multnomah, 1992

Yarbrough, Robert W. 1-3 John. BECNT; Grand Rapids, Michigan: Baker Academic, 2008.

Young, Sarah, Jesus' Calling: Enjoying Peace in His Presence (Nashville, Tennessee: Thomas Nelson, 2004.

Zuck, Roy B. “The Role of Holy Spirit in Hermeneutics," BSac., 141 (1984): 125. 